\title{
Tracing historical changes, degradation, and original sources of airborne polycyclic aromatic hydrocarbons (PAHs) in Jilin Province, China, by Abies holophylla and Pinus tabuliformis needle leaves
}

\section{Zhao Wang \\ Yanbian University \\ Xiangzi Jin \\ Yanbian University \\ Han Yeong Kaw \\ Zhejiang University \\ Zakia Fatima \\ Yanbian University \\ Maurizio Quinto}

University of Foggia Department of Agricultural Food and Environmental Sciences: Universita degli Studi di Foggia Dipartimento di Scienze Agrarie degli Alimenti e dell'Ambiente

John L. Zhou

University of Technology Sydney

Dongri Jin

Yanbian University

\section{Miao He}

Yanbian University

Donghao Li ( $\sim$ dhli@ybu.edu.cn )

Key Laboratory of Nature Resource of the Changbai Mountain and Functional Molecular (Yanbian University), Ministry of Education https://orcid.org/0000-0002-7033-6672

\section{Research Article}

Keywords: Polycyclic aromatic hydrocarbons (PAHs), Air pollution, Biomonitoring, PAH degradation constants, Abies holophylla, Pinus tabuliformis

Posted Date: July 13th, 2021

DOI: https://doi.org/10.21203/rs.3.rs-269882/v2 
License: (c) (i) This work is licensed under a Creative Commons Attribution 4.0 International License. Read Full License

Version of Record: A version of this preprint was published at Environmental Science and Pollution Research on August 31st, 2021. See the published version at https://doi.org/10.1007/s11356-021-161764. 
1 Tracing historical changes, degradation, and original sources of airborne

2

3

polycyclic aromatic hydrocarbons (PAHs) in Jilin Province, China, by Abies

holophylla and Pinus tabuliformis needle leaves

Zhao Wang ${ }^{\mathrm{a}}$, Xiangzi Jin ${ }^{\mathrm{a}}$, Han Yeong Kaw ${ }^{\mathrm{b}}$, Zakia Fatima ${ }^{\mathrm{a}}$, Maurizio Quinto ${ }^{\mathrm{a}, \mathrm{c}}$, John L.

Zhou ${ }^{\mathrm{d}}$, Dongri Jin ${ }^{\mathrm{a}}$, Miao He ${ }^{\mathrm{a},{ }^{* *}}$, Donghao $\mathrm{Li}^{\mathrm{a}}{ }^{,}$

a Department of Chemistry, Funtional Molecular Biology, Key Laboratory of Changbai Mountain Biological Resources and Functional Molecules, Yanbian University, Park Road 977, Yanji City, Jilin Province, 133002, PR China

${ }^{\mathrm{b}}$ Department of Environmental Science, Zhejiang University, Hangzhou, 310058, PR China.

${ }^{\mathrm{c}}$ DAFNE - Department of Agriculture, Food, Natural Resources and Engineering, University of Foggia, via Napoli 25, I-71122 Foggia, Italy.

${ }^{\mathrm{d}}$ Centre for Green Technology, School of Civil and Environmental Engineering, University of Technology Sydney, 15 Broadway, NSW, 2007, Australia.

${ }^{*}$ Corresponding author.

${ }^{* *}$ Co-corresponding author.

E-mail addresses: dhli@ybu.edu.cn (D. Li); hemiao@yby.edu.cn (D. Jin); Department of Chemistry, Yanbian University, Park Road 977, Yanji City, Jilin Province, 133002, PR China. 
Abstract: Due to their wide distribution and availability, plant leaves can be considered interesting candidates as biomonitoring substrates for the evaluation of atmospheric pollution. In addition, some species can also retain historical information, for example, related to environmental pollution, due to their leaf class age. In this study, the content of polycyclic aromatic hydrocarbons (PAHs) in Abies holophylla and Pinus tabuliformis needle samples in function of their class age has been investigated to obtain information regarding the degradation constant for each PAH under investigation ( $\alpha$ values ranging from 0.173 to 1.870 ) and to evaluate the possibility to correlate the presence of PAHs in needles with some important pollution environmental factors. Considering air pollutant variables registered in Jilin Province, significant correlations (at 95\% confidence level) have been found between coal consumption per year and anthracene contents in needles, while fluorene, phenanthrene, and anthracene resulted correlated with coal consumption. Furthermore, it has been demonstrated that the total PAH concentration in needles, for both species, increased with their age (from 804 to $3604 \mathrm{ng}$ $\mathrm{g}^{-1}$ dry weight), showing a general tendency to accumulate these substances through years. PAH degradation rates increased instead with molecular complexity. This study could be considered a first trial to obtain historical environmental information by pine needles biomonitoring.

Keywords: Polycyclic aromatic hydrocarbons (PAHs); Air pollution; Biomonitoring; PAH degradation constants; Abies holophylla; Pinus tabuliformis 


\section{Introduction}

The presence of polycyclic aromatic hydrocarbons (PAHs) in the atmosphere represents one of the problems of major concern related to air pollution in recent decades. Airborne PAHs are produced by incomplete combustion of industrial emissions and transportation (Rodgman et al. 2000; Chang et al. 2006), as well as wildfire (Choi 2014; Lao et al. 2018), and their monitoring has been considered a challenging activity, due to the carcinogenic, mutagenic, and teratogenic effects of these substances on human health (International Agency for Research on Cancer 1983; Hopkins 1989). PAHs determination, anyway, could encounter technical, physical, and economical limitations when active air samplers are used, while sampling tree components like needles, leaves and barks, suitable for the determination of the spatial distribution of PAHs, are usually employed only to measure the current levels of atmospheric PAHs (De Nicola et al. 2011; Amigo et al. 2011; Zhou et al. 2014). Recent studies on the historical record of PAHs have been conducted in lake sediments and ice cores of specific areas (Wang et al. 2008; Cai et al. 2016), but these sampling sites impose several constraints, limiting the monitoring to specific conditions in terms of spatial recognition and time intervals.

Plants can be considered a very interesting and advantageous biomonitoring substrate in particular for $\mathrm{PAH}$ monitoring, due to the hydrophobic lipid layers that can retain these substances (Paterson et al. 1991; Kim et al. 2014). For example, it has been demonstrated that diffusive uptake and storage function of polymeric lipids of plants play a key role in the transport and fate of phenanthrene (Li and Chen 2014). A unique and very useful characteristic of conifer needles is that they can grow up and last for several years, thus preserving the history of the environmental conditions (Navarro-Ortega et al. 2012; Noth et al. 2013; FernándezVarela et al. 2015). Furthermore, some PAHs can be used as a marker of certain pollution sources: for example, it was found that the prevalence of lower molecular weight PAHs in ambient air samples can be essentially related to the road traffic, more specifically with vehicles of diesel engines (Albuquerque et al. 2016). Studies on some specific PAH content ratios in needles, such as anthracene/(anthracene + phenanthrene) or fluoranthene/(fluoranthene + 
pyrene), have been carried out to identify local sources of contamination (Esen et al. 2008; Galarneau 2008; Kong et al. 2015).

In this study, Abies holophylla needles from 1 to 6 years old $(2016$ - 2011) and Pinus tabuliformis from 1 to 4 years old (2015 - 2012) have been collected to investigate the speciesspecificity historical variations of PAHs and to examine the possible relation between emitted air pollutants and PAHs in the needles over the years. To pursue this target, PAH degradation has been taken into consideration using a first-order kinetic mechanism already used to interpret the PAH degradation process (Wammer and Peters 2005). Finally, through a statistical approach, potential correlations between PAH contents in conifer needles and data relevant to pollutant sources of airborne PAHs in Jilin Province have been investigated.

\section{Material and methods}

\subsection{Materials and standards}

Standard mixtures of $16 \mathrm{PAHs}$ (naphthalene (Naph), acenaphthylene (Acy), acenaphthene (Ace), fluorene (Fluo), phenanthrene (Phen), anthracene (Ant), fluoranthene (Flt), pyrene (Pyr), benzo[a]anthracene $(\mathrm{BaA})$, chrysene (Chry), benzo[b]fluoranthene (BbF), benzo[k]fluoranthene (BkF), benzo[a]pyrene (BaP), indeno[1,2,3-cd] pyrene (IcdP), dibenzo[a,h]anthracene (DahA) and benzo[ghi]perylene (BghiP)) and 3 deuterated PAHs (Phenanthrene- $\mathrm{d}_{8}$, Fluoranthene- $\mathrm{d}_{12}$ and Perylene- $\mathrm{d}_{12}$ ) were purchased from Sigma Aldrich (St. Louis, MO, USA). The purity of all standards was up to $98 \%$. Silica (100-200 mesh) and $\mathrm{Al}_{2} \mathrm{O}_{3}$ adsorbent were obtained from Sigma Aldrich (St. Louis, MO, USA). To remove the contaminants, all adsorbents and glassware were heated at $400^{\circ} \mathrm{C}$ for $12 \mathrm{~h}$.

\subsection{Sampling and processing}

The sampling site was located on the west side of the Changbai Mountains, in the southeast of Jilin Province, China. A detailed map of the sampling sites is reported in the Supplementary Information (Online resource 1). Three different trees of Pinus tabuliformis and Abies holophylla were chosen as sampling representative plants. Then, from each of them, leaf 
samples (collected in October 2015 and October 2016) were selected and subdivided in function of their age (vide infra), obtaining six fractions for Abies holophylla and four fractions for Pinus tabuliformis, respectively. This sampling plan led to a total of 30 needle samples $(3$ trees $\times 4$ different needle ages for Pinus tabuliformis, and 3 trees $\times 6$ different needle ages for Abies holophylla). The age of needles was evaluated following the directives of Pérez-Harguindeguy et al. (Pérez-Harguindeguy et al. 2013), counting the number of rings of a branch cut close to the needle samples (Fig. 1). In order to ensure the best sampling representativeness, needles of the same year, collected between the upper $1 / 3$ and lower $1 / 3$ of the tree species canopy, were mixed into one sample, and successively cleaned, freeze-dried, and crushed by 200 mesh. The choice of this sieving grid dimension has been chosen on the basis of preliminary experiments, which demonstrated that higher mesh values lead to a large sample loss during the sieving process, while lower mesh values allow larger tissue shreds to pass through the mesh, making the extraction process less efficient. Finally, if not directly analyzed, samples were stored at $20^{\circ} \mathrm{C}$.
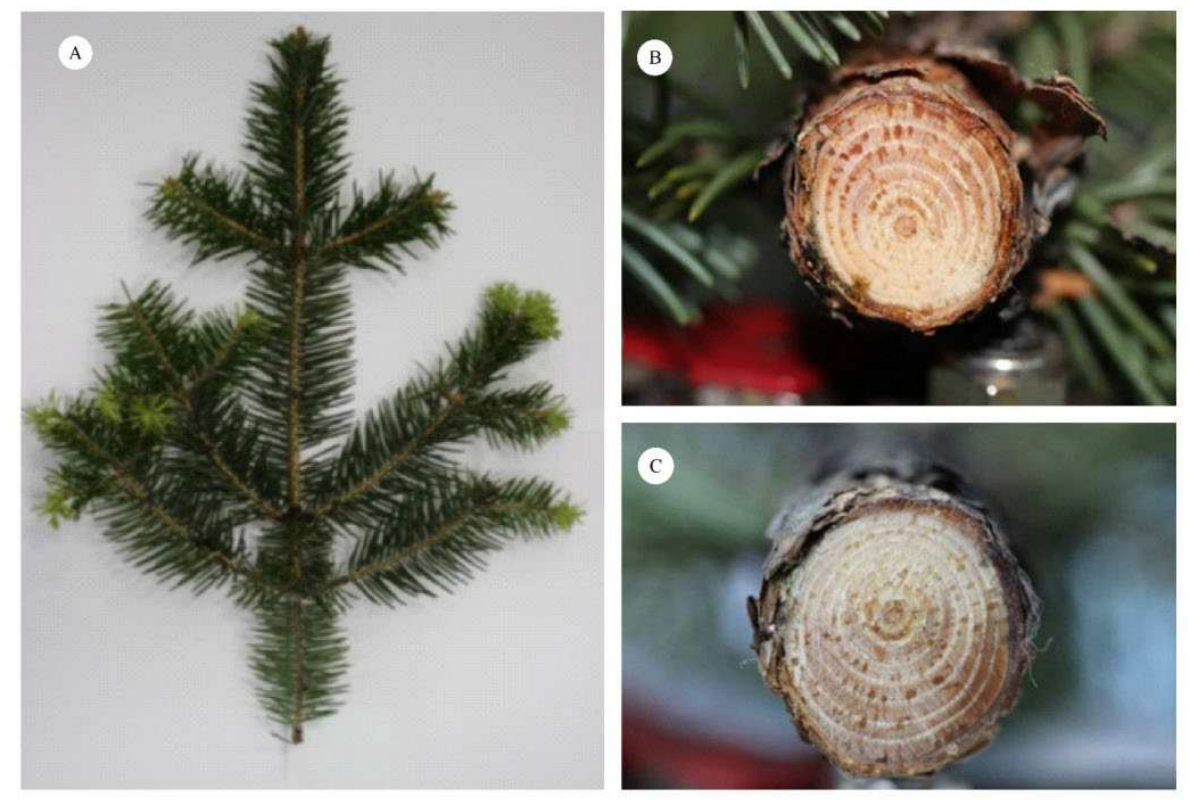

Fig. 1 Photographs that show the branch information of A) Abies holophylla, and the growth ring patterns of B) Abies holophylla and C) Pinus tabuliformis.

Eleven air pollutant emission variables with an expected environmental impact on the PAH 
concentrations, namely: coal (Ton year $\left.{ }^{-1}\right)$, crude oil $\left(\right.$ Ton year $\left.^{-1}\right)$, and electricity (MKh year ${ }^{-1}$ ) consumption; number of civil vehicles and trucks $\left(\right.$ Unit year $\left.^{-1}\right)$; emission of industrial sulfur, nitrogen oxide, industrial smoke (dust), and soot (Ton year ${ }^{-1}$ ); urban living gaseous pollutant emissions (Ton year ${ }^{-1}$ ); generating capacity $\left(\mathrm{KWh} \mathrm{year}^{-1}\right)$, were obtained for the relevant areas from the databases of the Jilin Provincial Bureau of Statistic (Jilin Province Statistics Bureau Data Management Center 2020).

\subsection{Measurement of lipid content}

Needle lipid contents were measured as follows: $3 \mathrm{~g}$ of dry needles were extracted 3 times using ultrasonication with $20 \mathrm{~mL}$ of $\mathrm{n}$-hexane: acetone (50:50,v/v) for 20 min each. The extract was concentrated, dried and finally weighed to calculate the lipid content (Zhao et al. 2018).

\subsection{PAHs analysis}

\subsubsection{Extraction of PAHs}

Sample pre-treatment procedures were performed according to a method already described in our previous publication, with slight modifications (Jin et al. 2020). In brief, a total of $0.5 \mathrm{~g}$ homogenized, crushed, and sieved needle powder was spiked with internal standards, then mixed with $10 \mathrm{~mL}$ of dichloromethane (DCM) and ultrasonically extracted 3 times per $15 \mathrm{~min}$. The combined extract was dried under a gentle stream of nitrogen, replaced with $\mathrm{n}$-hexane, and concentrated to $0.5 \mathrm{~mL}$ prior to SPE clean-up. The SPE column (down-top: $2.0 \mathrm{~g} \mathrm{Na} 2 \mathrm{SO}_{4}, 1.5$ g silica gel, $0.8 \mathrm{~g} \mathrm{Al}_{2} \mathrm{O}_{3}$ deactivated with $2 \%$ ultrapure water, and $4.0 \mathrm{~g} \mathrm{Na}_{2} \mathrm{SO}_{4}$ ) was conditioned with $n-$ hexane before sample loading. Then, the extract was eluted with $3 \mathrm{~mL} n-$ hexane (discarded) followed by $9 \mathrm{~mL} \mathrm{n}-$ hexane/DCM $(50: 50, \mathrm{v} / \mathrm{v})$. The last $6 \mathrm{~mL}$ of the eluted solution were collected and concentrated under a gentle stream of nitrogen gas at room temperature, and subsequently reconstituted with $100 \mu \mathrm{L}$ of $\mathrm{n}$-hexane. Then, gas purge microsyringe extraction (GP-MSE) was used for further purification, as described in a previous work (Yang et al. 2011), and the final volume was adjusted to $100 \mu \mathrm{L}$. Finally, $2 \mu \mathrm{L}$ of the purified extract was injected into the gas chromatograph-mass spectrometer (GC-MS) for the 
relevant analysis. All the samples were extracted in duplicate.

\subsubsection{GC-MS analysis}

PAH analyses were carried out by a Shimadzu GC equipped with a DB-5MS fused silica capillary column ( $30 \mathrm{~m} \times 0.25 \mathrm{~mm}$; thickness: $0.25 \mu \mathrm{m}$, Restek Corporation, Bellefonte, PA, USA) connected with a QPMS 2010 MS detector. GC-MS instrumental conditions were as follows: sample injection was carried out in splitless mode at $280^{\circ} \mathrm{C}$, using $\mathrm{He}$ as a carrier gas at a flow rate of $1 \mathrm{ml} \mathrm{min}{ }^{-1}$. GC-MS interface temperature was set at $280^{\circ} \mathrm{C}$, ionization voltage was $70 \mathrm{eV}$, and ion source temperature was set at $200^{\circ} \mathrm{C}$. The initial oven temperature was held at $80^{\circ} \mathrm{C}$ for $1 \mathrm{~min}$, then was brought to $100^{\circ} \mathrm{C}$ at the rate of $20^{\circ} \mathrm{C} \mathrm{min}{ }^{-1}$, from $100^{\circ} \mathrm{C}$ to $200^{\circ} \mathrm{C}$ at $10^{\circ} \mathrm{C} \mathrm{m^{-1 }}$ and $200^{\circ} \mathrm{C}$ to $280^{\circ} \mathrm{C}$ at $20^{\circ} \mathrm{C} \mathrm{min}^{-1}$, holding this last value for $2 \mathrm{~min}$. Selected ion monitoring mode (SIM) was selected for data collection.

\subsection{Method validation}

As recommended by the European Decision 657/2002/EC (European Community 2002), the validation of the analytical methods is essential to provide reliable results in official controls for pesticide determinations. Therefore, the analytical method was extensively validated through the evaluation of selectivity, linearity, detection and quantification limits, precision, recovery, and ruggedness. 7The absence of interfering peaks in the retention time window of interest was checked for each analyte within the retention time tolerance of $0.2 \mathrm{~min}$. The trueness of measurements was assessed through the recovery of additions of known amounts of the analytes to a blank matrix. Precision and recovery were determined by performing tests on two sets of blank samples $(n=6)$, fortified with PAHs, each at a concentration of $200 \mathrm{ng} \mathrm{mL}^{-1}$. Spiked PAH samples at a concentration of $200 \mathrm{ng} \mathrm{mL}^{-1}(\mathrm{n}=6)$ were analyzed for the validation of the method in real samples. The experiments were carried out on different days with the same instruments but by different operators, to ensure the greater variability of results. Limit of detections (LODs) in leaf samples, calculated by 3 times the signal-to-noise ratios, were in the range $0.02-0.08 \mathrm{ng} \mathrm{g}^{-1}$. PAH method detection limits (MDLs), calculated as described by Jin 
et al. (Jin et al. 2020), were in the range $0.2-5.1 \mathrm{ng} \mathrm{g}^{-1}$. Under the optimized conditions, recoveries obtained for standard solutions ranged from 79 to $99 \%$, while for matrix spiked samples these values were from 64 to $120 \%$. The relative percentage difference for individual PAH determined in paired duplicate samples $(n=2)$ was always $<24 \%$. The obtained recovery for all the PAHs was between $64 \%$ and $120 \%$ with respect to the certified values.

\subsection{Statistical data treatment}

Precision and recovery data have been previously processed by the Shapiro-Wilk test (Shapiro and Wilk 1965) to verify normal distribution. Afterward, a one-way ANOVA test was performed to verify the homogeneity of the mean concentration values evaluated among the validation sessions at each fortification level. The method reliability was assessed by the analysis of blank samples $(n=6)$, standard solutions $(n=18)$, and spiked samples $(n=6)$. In the case of blank samples, no significant response at 95 confidence level was observed for all PAHs.

\section{Results and discussion}

\subsection{Adsorbed PAHs in needles}

Usually, the PAH content in plant samples is normalized by lipid content or dry weight. Studies have shown that both cuticle and suberin (a cell wall component) may act as lipids in different parts of the plant, but they are not solvent extractable (Ockenden et al. 1998; Taiz and Zeiger 2010; Chen et al. 2012). For this reason, the needle lipid content obtained by these methods may not reflect the total amount of PAH extracting substances. The needle lipid contents in Abies holophylla and Pinus tabuliformis ranged from 27.46 to $32.16 \%$, and from 6.85 to $9.56 \%$ (respect to dry weight), respectively (Online Resource 2). These values are significantly different (at 95\% confidence level) and undoubtedly influence the tendency of different species to accumulate PAHs in the needles. In fact, Abies holophylla needles showed a higher propensity to accumulate PAHs with respect to Pinus tabuliformis needles. On the other hand, when a single tree species is considered, no significant correlation between lipid 
content and PAH contents was found $(\mathrm{R}=-0.12-0.646, \mathrm{p}>0.354)$. Hence, in this study PAH contents were expressed on a dry weight basis. The sum of PAH contents found in leaf extracts ( $\mathrm{PAHs}$ ) are listed in Table 1. As expected, due to the accumulating effect, $\Sigma$ PAHs generally increase with the needle age, in accordance with the results obtained by previous works (Ratola et al. 2010a; Odabasi et al. 2015).

Table 1 PPAHs (expressed on a dry weight basis) in Abies holophylla and Pinus tabuliformis as a function of needle age.

\begin{tabular}{ccccccc}
\hline \multirow{2}{*}{ Rings } & \multicolumn{5}{c}{ Abies holophylla $\left(\mathbf{n g ~ g}^{-1}\right)(\mathbf{n}=\mathbf{1 8})$} \\
\cline { 2 - 6 } & $\mathbf{2 0 1 6}$ & $\mathbf{2 0 1 5}$ & $\mathbf{2 0 1 4}$ & $\mathbf{2 0 1 3}$ & $\mathbf{2 0 1 2}$ & $\mathbf{2 0 1 1}$ \\
\hline 2 & $43 \pm 2$ & $52 \pm 17$ & $42 \pm 5$ & $38 \pm 1$ & $38 \pm 2$ & $45 \pm 7$ \\
3 & $981 \pm 76$ & $1503 \pm 10$ & $1669 \pm 13$ & $1820 \pm 82$ & $2135 \pm 149$ & $2340 \pm 34$ \\
4 & $438 \pm 133$ & $588 \pm 98$ & $762 \pm 204$ & $815 \pm 158$ & $893 \pm 84$ & $1228 \pm 130$ \\
5,6 & $18 \pm 1$ & $14 \pm 1$ & $9 \pm 2$ & $16 \pm 2$ & $10 \pm 4$ & $21 \pm 7$ \\
Total PAHs & $1449 \pm 212$ & $2113 \pm 106$ & $2446 \pm 189$ & $2663 \pm 73$ & $3044 \pm 67$ & $3604 \pm 96$ \\
\hline
\end{tabular}

\begin{tabular}{ccccc}
\hline \multirow{2}{*}{ Rings } & \multicolumn{4}{c}{ Pinus tabuliformis $\left(\mathbf{n g ~ g}^{-1}\right)(\mathbf{n}=\mathbf{1 2})$} \\
\cline { 2 - 5 } & $\mathbf{2 0 1 5}$ & $\mathbf{2 0 1 4}$ & $\mathbf{2 0 1 3}$ & $\mathbf{2 0 1 2}$ \\
\hline 2 & $119 \pm 4$ & $100 \pm 1$ & $105 \pm 25$ & $72 \pm 8$ \\
3 & $498 \pm 112$ & $829 \pm 102$ & $845 \pm 66$ & $910 \pm 39$ \\
4 & $152 \pm 10$ & $241 \pm 22$ & $319 \pm 51$ & $308 \pm 30$ \\
5,6 & $34 \pm 7$ & $28 \pm 3$ & $65 \pm 39$ & $145 \pm 77$ \\
Total PAHs & $804 \pm 99$ & $1197 \pm 127$ & $1334 \pm 131$ & $1435 \pm 93$ \\
\hline
\end{tabular}

3-4 ring PAH contents were found to be higher than 5-6 ring PAHs: this result is in good agreement with the PAH accumulation pattern in needles of other pine species, including Pinus halepensis and Pinus pinea (Librando et al. 2002), Pinus pinaster and Pinus nigra (Piccardo et al. 2005) and Pinus pinaster and Pinus pinea (Ratola et al. 2010a). The accumulation process may anyway vary from species to species, leading to a different concentration in needles (Ratola et al. 2011). This behavior has been noticed also for the species in this work, even if a similar PAH trend for years 1 to 4 with Abies holophylla and Pinus tabuliformis needles were noticed. More than $64 \%$ of adsorbed PAHs in the needles are composed of 3-4 ring PAHs: this value roughly reflects PAH composition in the air in both urban and industrial areas (Tomashuk et al. 
2012; Odabasi et al. 2015; Li et al. 2016). The low content of 5-6 ring PAHs observed confirms what already noticed in previous works (Albuquerque et al. 2016; Liu et al. 2017) and it is prevalently due to their concentration in air, which is generally lower compared to the other PAHs and by their different distribution in the environment. These PAHs are present, in fact, preferentially in the particulate phase of the atmosphere, and for this reason, their migration from the atmosphere can be slower if compared with other PAHs (Yang et al. 2017). Furthermore, the low content of 5-6 ring PAHs could be also related to the fact that their adsorption in needle leaves is more difficult due to their dimensions (Yang et al. 2007). 3-4 ring PAHs, which are predominantly present in the gaseous phase, interact strongly with the waxy layer of the needles and this effect can promote PAH uptakes in needles (Lehndorff and Schwark 2004). With regards to Naph, its volatile nature, its fast photodegradation process, and its resuspension capability lead to an unstable accumulation in the needles (Wang et al. 2005; Choi 2014)

\subsection{PAH degradation constants in Abies holophylla needles}

As already pointed out, PAHs are present in gas and particle phases of the atmosphere and diffuse into plant leaves through dry and wet deposition. Their sources are closely related to the anthropogenic combustion processes (e.g., car exhaust, local heating facilities, industrialrelated activities). It has been already demonstrated that the PAH degradation follows a firstorder kinetics (Wammer and Peters 2005; Haritash and Kaushik 2009), even if dependent on external variables, like, for example, fly ash and carbon black, that can protect PAHs from photodecomposition (Behymer and Hites, 1985; Korfmacher et al. 1979). Hence, it could be hypothesised the PAH amount collected in different years by needles undergo a degradation mechanism that follows an exponential trend. Considering, as a first approximation, that the first-order degradation kinetic constant does not change over the years, the PAH total content in leaves can be described by this equation:

$$
C_{\text {year }}^{\text {Tot }}=\sum_{i=0}^{n} C_{i} e^{-\alpha t_{i}}
$$


Where $C_{\text {year }}^{\text {Tot }}$ is the content (obtained experimentally) for each $\mathrm{PAH}, C_{i}$ is the PAH amount that can be attributed to a specific year, $\alpha$ is the degradation kinetic constant and $t_{i}$ is the time expressed in years. This model was then applied to PAH contents in Abies holophylla needles, considering that, for this species, data were collected from 2011 to 2016. In this case, it is possible to write for each year the following equations:

$$
\begin{array}{lr}
C_{2011}^{T o t}=C_{\leq 2010} e^{-\alpha}+C_{2011} & \text { Eq.2 } \\
C_{2012}^{T o t}=C_{\leq 2010} e^{-2 \alpha}+C_{2011} e^{-\alpha}+C_{2012} & \text { Eq.3 } \\
C_{2013}^{T o t}=C_{\leq 2010} e^{-3 \alpha}+C_{2011} e^{-2 \alpha}+C_{2012} e^{-\alpha}+C_{2013} & \text { Eq.4 } \\
C_{2014}^{T o t}=C_{\leq 2010} e^{-4 \alpha}+C_{2011} e^{-3 \alpha}+C_{2012} e^{-2 \alpha}+C_{2013} e^{-\alpha}+C_{2014} & \text { Eq.5 } \\
C_{2015}^{T o t}=C_{\leq 2010} e^{-5 \alpha}+C_{2011} e^{-4 \alpha}+C_{2012} e^{-3 \alpha}+C_{2013} e^{-2 \alpha}+C_{2014} e^{-\alpha}+C_{2015} & \text { Eq.6 } \\
C_{2016}^{T o t}=C_{\leq 2010} e^{-6 \alpha}+C_{2011} e^{-5 \alpha}+C_{2012} e^{-4 \alpha}+C_{2013} e^{-3 \alpha}+C_{2014} e^{-2 \alpha}+C_{2015} e^{-\alpha}+C_{2016} & \text { Eq.7 }
\end{array}
$$

Considering $e^{-\alpha t}=y$ we have:

$$
\begin{aligned}
& C_{2011}^{T o t}=C_{\leq 2010} y+C_{2011} \\
& C_{2012}^{T o t}=C_{\leq 2010} y^{2}+C_{2011} y+C_{2012}=\left(C_{\leq 2010} y+C_{2011}\right) y+C_{2012}=C_{2011}^{T o t} y+C_{2012}
\end{aligned}
$$

and then, applying the same elaboration to other years:

$$
\begin{aligned}
& C_{2013}^{T o t}=C_{2012}^{T o t} y+C_{2013} \\
& C_{2014}^{T o t}=C_{2013}^{T o t} y+C_{2014} \\
& C_{2015}^{T o t}=C_{2014}^{T o t} y+C_{2015} \\
& C_{2016}^{T o t}=C_{2015}^{T o t} y+C_{2016}
\end{aligned}
$$

On the basis of Eq. 9-13, considering that $C_{\text {year }}$ and $y$ should be always $\geq 0$, it is possible to individuate the minimum acceptable $\alpha$ values and the relevant minimum PAH degradation percentage per year (Table 2) that satisfy this condition. Different works (Cutright 1995; Kästner et al. 1998; Johnsen et al. 2005) reported studies to determine the specific degradation rates for the bioremediation of PAH-contaminated soils, but, to our knowledge, no studies have been carried out regarding the PAH degradation in leaves.

Table 2 Minimum percentage of PAH degradation year $^{-1}$ and minimum values of the degradation 
constant.

\begin{tabular}{cccc}
\hline Rings & Compound & Minimum degradation per year (\%) & Minimum $\boldsymbol{\alpha}$ value \\
\hline 2 & Naph & 32 & 0.387 \\
3 & Acy & 16 & 0.173 \\
3 & Ace & 34 & 0.421 \\
3 & Fluo & 39 & 0.501 \\
3 & Phen & 27 & 0.309 \\
3 & Ant & 41 & 0.533 \\
3 & Flt & 35 & 0.428 \\
4 & Pyr & 35 & 0.423 \\
4 & BaA & 39 & 0.496 \\
4 & Chry & 32 & 0.382 \\
4 & BbF & 35 & 0.434 \\
4 & BkF & 62 & 0.962 \\
4 & BaP & 25 & 0.987 \\
5 & IcdP & 81 & 1.681 \\
5 & DahA & 85 & 1.870 \\
6 & BghiP & 81 & 1.647 \\
\hline
\end{tabular}

It is interesting to note that our results showed that the higher is the number of rings (i.e. IcdP, DahA and BghiP), the higher is the degradation constant, while it has been demonstrated that the degradation rate of high molecular weight PAHs in soil is slower than other PAHs (Johnsen et al. 2005; Roslund et al. 2018). This different behavior is most probably ascribable to the different degradation mechanisms in soil and needles: in the first case, it is governed by bacteria activity, while in needles is mostly dependent on PAH chemical stability. The proposed degradation model allows an estimation of the PAH contents retained by needles every year. Fig. 2 shows the normalized PAH content intervals in needles, with lower and upper limits obtained considering the minimum $\alpha$ value listed in Table 2 and the maximum PAH degradation rates (i.e., $\mathrm{e}^{-\alpha \mathrm{t}} \simeq 0$ ), respectively. 3-4 ring PAHs show a decrease from 2011 to 2016, while for 2 and 5-6 ring PAHs the behavior seems not to follow any particular trend. 


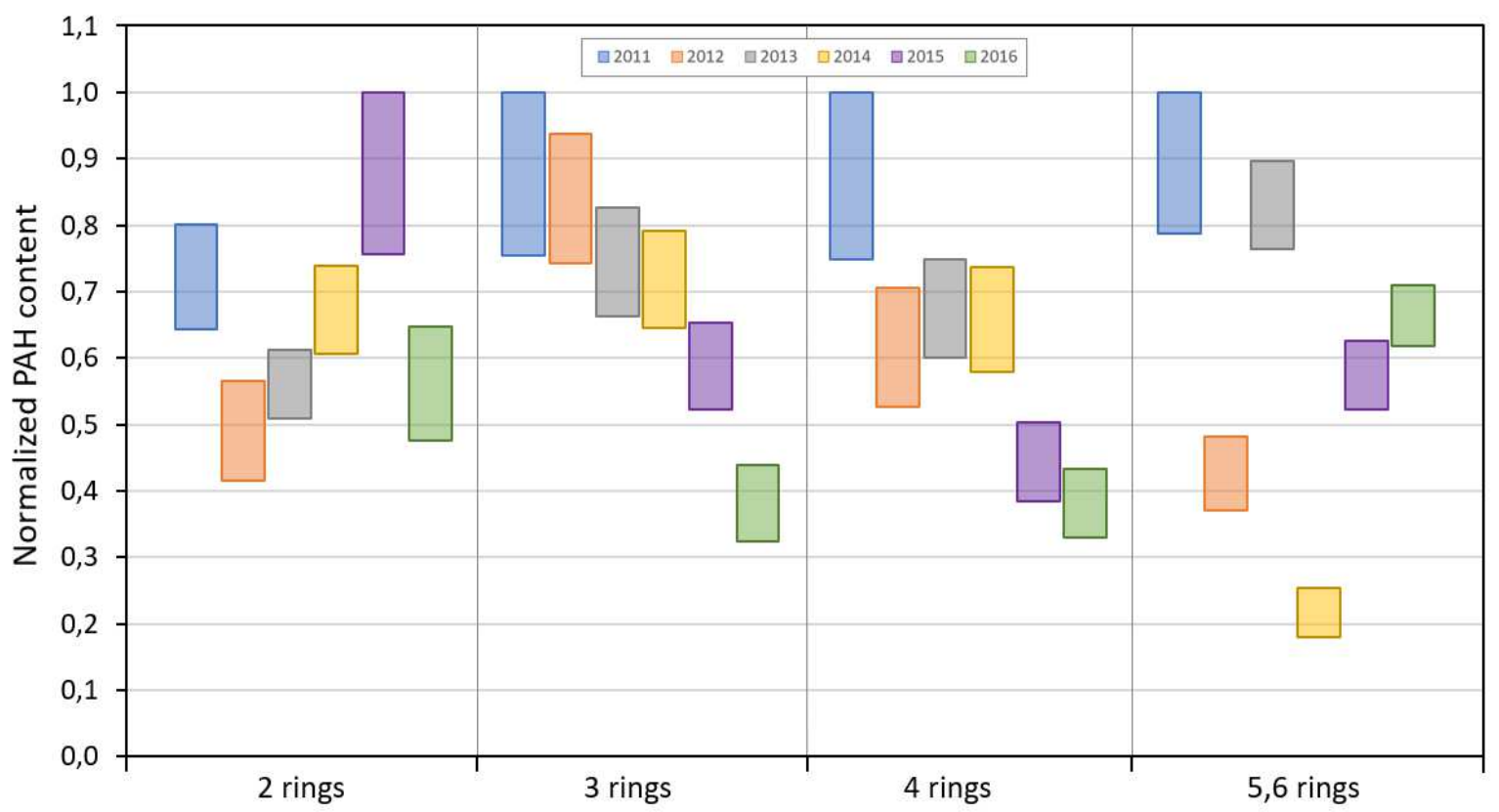

Fig. 2 Normalized PAH content intervals in needles (calculated taking into account the PAH maximum concentration value for each ring class) through the years. Lower and upper limits have been obtained considering the minimum $\alpha$ value listed in Table 2 and the maximum PAH degradation rates (i.e., $\mathrm{e}^{-\alpha t} \simeq 0$ ), respectively.

\subsection{Correlations between adsorbed PAHs in Abies holophylla needles and air pollutant emission variables in needles}

PAH sources are closely related to the anthropogenic combustion processes (e.g., car exhaust, local heating facilities, industrial-related activities). It has been already demonstrated that the presence of PAHs in Jilin Province area is mainly due to long-distance transportation and anthropogenic emission (Zhao et al. 2015). Then, it could be hypothesized a correlation between adsorbed PAHs and some air pollutant emission parameters, even if clearly influenced by the main wind in the sampling site, which is west-northwest in the spring, autumn, and winter, and southeast-southwest during the summer. From Jilin Provincial Bureau of Statistic (Jilin Province Statistics Bureau Data Management Center 2020), it has been possible to obtain data on the sampling areas concerning annual consumption of coal (Ton year ${ }^{-1}$ ), crude oil (Ton year $^{-1}$ ) and electricity (MKh year ${ }^{-1}$ ) consumption; number of civil vehicles and trucks (Unit year $^{-1}$ ); emission of industrial sulfur, nitrogen oxide, industrial smoke (dust), and soot (Ton 
year $\left.{ }^{-1}\right)$; urban living gaseous pollutant emissions $\left(\right.$ Ton year $\left.^{-1}\right)$; generating capacity $\left(\mathrm{KWh}_{\text {year }}\right.$ $\left.{ }^{1}\right)$ (Online resource 3). Correlation coefficients were then obtained by linear regression considering these parameters and PAH average values from Abies holophylla. These values are reported in Table 3, where the most statistically significant correlations have been reported $(\mathrm{R}>$ $0.8)$.

Table 3 Correlation coefficients $(\mathrm{R})$ obtained by linear regression between air pollution parameters and the average values of adsorbed PAHs obtained from Abies holophylla. Only R $>0.8$ values are displayed. All these parameters are statistically significant $(\alpha=0,01, \mathrm{n}=18)$.

\begin{tabular}{|c|c|c|}
\hline Air pollutant parameter & PAH & Correlation coefficient (R) \\
\hline \multirow{4}{*}{ Coal } & Fluo & 0.817 \\
\hline & Phen & 0.947 \\
\hline & Ant & 0.874 \\
\hline & Flt & 0.915 \\
\hline \multirow{3}{*}{ Electricity } & Pyr & 0.925 \\
\hline & $\mathrm{BaA}$ & 0.906 \\
\hline & Chry & 0.947 \\
\hline Trucks & $\mathrm{BbF}$ & 0.814 \\
\hline \multirow{5}{*}{ Industrial sulfur emissions } & Fluo & 0.862 \\
\hline & Phen & 0.857 \\
\hline & Acy & 0.869 \\
\hline & Ace & 0.982 \\
\hline & Fluo & 0.956 \\
\hline \multirow[t]{4}{*}{ Industrial nitrogen oxide emissions } & Phen & 0.934 \\
\hline & Ant & 0.848 \\
\hline & Flt & 0.908 \\
\hline & Pyr & 0.833 \\
\hline \multirow[t]{2}{*}{ Vehicle number } & $\mathrm{BaP}$ & 0.888 \\
\hline & Ace & 0.816 \\
\hline \multirow[t]{3}{*}{ Industrial gaseous pollutant emissions } & Fluo & 0.866 \\
\hline & Phen & 0.864 \\
\hline & Flt & 0.915 \\
\hline \multirow{3}{*}{ Generating capacity } & Pyr & 0.925 \\
\hline & $\mathrm{BaA}$ & 0.911 \\
\hline & Chry & 0.947 \\
\hline
\end{tabular}

Some interesting considerations can be made based on Table 3. For instance, Phen, Fluo, and Ant (with correlation coefficients equal to $0.947,0.915$, and 0.874 , respectively) are well 
correlated with coal consumption, and this correlation can be ascribed to their large production during this process (Dameng et al. 2011). On the other hand, these three PAHs are not the only ones produced during coal combustion, but for these others, the lack of correlation could be due to interfering processes. The correlation existing between the number of trucks and $\mathrm{BbF}$ can be ascribed to its production by diesel engines (Kuusimäki et al. 2002). It is also worth to note the high number of PAH that are correlated with industrial nitrogen oxide emissions, suggesting that NOx production can be strongly related to the emission of these PAHs in the atmosphere. Fig. 3 shows a typical correlation graph obtained between coal consumption per year and Ant contents in needle.

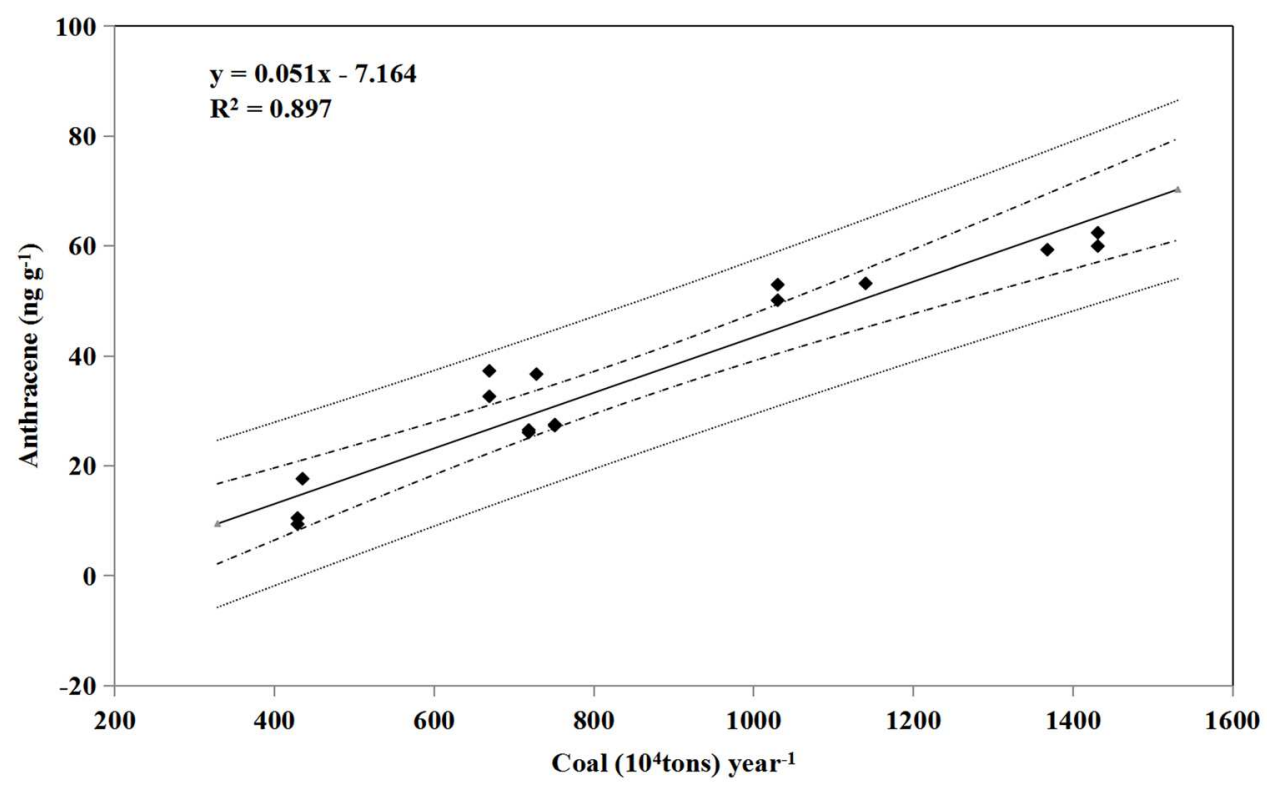

Fig. 3 Correlation between coal consumption per year and anthracene content in Abies holophylla leaves. The solid line and dotted line curves represent confidence limits for the prediction and confidence limits for the regression line at $95 \%$ confidence level, respectively.

In the urban areas, traffic emission is the dominant source of PAHs (Ratola et al. 2010b), in particular for 3-4 ring PAHs: this could explain the significant correlation (at 95\% confidence level) between vehicle number and BaP. Surprisingly, none of the 5-6 ring PAHs shows correlation with any of the pollution sources, probably because of their fast degradation constant $(\alpha \geq 1.65)$ that does not allow to acquire time dependent information from needles, and to the molecule dimensions, that make more difficult their adsorption into pine needles (Yang et al. 

2007).

\section{Conclusions}

In this study, the possibility to evaluate PAH historical changes and their correlation with pollution emission sources by PAH contents in the needles of Abies holophylla and Pinus tabuliformis has been investigated. Using the PAH content in Abies holophylla needles, a mathematical model that considers a first-order PAH degradation process has been applied in order to obtain the minimum $\alpha$ value for each of the considered PAH. Results indicate that the higher is the number of rings (i.e. IcdP and DahA and BghiP), the higher is the degradation constant in the needles, with the consequence of high degradation rates. Furthermore, considering that PAH sources are closely related to the anthropogenic pollution processes, the adsorbed PAH content calculated by the mathematical model used in this work from 2011 to 2016 in Abies holophylla leaves has been statistically compared with air pollutant emission parameters achieved from the databases, obtaining in some cases correlation with $\mathrm{R}>0.8$ among data. The obtained results, which need further studies on a larger scale to confirm data and correlations here presented, indicate that adsorbed PAHs in needle leaves are good candidates as a biomonitoring system to evaluate the historical changes of PAHs induced by pollutant emission on the regional scale.

Author contributions Z.W., M.H. and D.L. conceptualized and designed the experiments. Z.W., X.J. and H.Y.K. performed the experiments. Z.W., M.Q. and J.L.Z. analyzed the data and made figures. Z.W., Z.F. and M.Q. wrote the paper. All the authors read and contributed to the submitted version of the manuscript. D.L. and M.H. acquired the funding and were responsible for resources.

Funding This study was supported by a grant from the National Natural Science Foundation of China (No. $21775134 \& 22066025)$ and the 111 Project (D18012).

Data Availability All relevant data are within the manuscript and available from the 
corresponding author upon request.

Compliance with ethical standards

Conflict of interest: The Authors declare that they have no conflict of interest

Ethical approval: Not applicable

Consent to participate: Not applicable

Consent to publish: Not applicable 


\section{References}

Albuquerque M, Coutinho M, Borrego C (2016) Long-term monitoring and seasonal analysis of polycyclic aromatic hydrocarbons (PAHs) measured over a decade in the ambient air of Porto, Portugal. Science of The Total Environment 543:439-448. https://doi.org/10.1016/j.scitotenv.2015.11.064

Amigo JM, Ratola N, Alves A (2011) Study of geographical trends of polycyclic aromatic hydrocarbons using pine needles. Atmospheric Environment 45:5988-5996. https://doi.org/10.1016/j.atmosenv.2011.07.058

Behymer TD, Hites RA (1985) Photolysis of polycyclic aromatic hydrocarbons adsorbed on simulated atmospheric particulates. Environmental Science \& Technology 19:10041006. https://doi.org/10.1021/es00140a020

Cai YZ, Wang XH, Wu YL, Li YY, Ya ML (2016) Over 100-year sedimentary record of polycyclic aromatic hydrocarbons (PAHs) and organochlorine compounds (OCs) in the continental shelf of the East China Sea. Environmental Pollution 219:774-784. https://doi.org/10.1016/j.envpol.2016.07.053

Chang KF, Fang GC, Chen JC, Wu YS (2006) Atmospheric polycyclic aromatic hydrocarbons (PAHs) in Asia: A review from 1999 to 2004. Environmental Pollution 142:388-396. https://doi.org/10.1016/j.envpol.2005.09.025

Chen P, Mei J, Peng P, Hu JF, Chen DY (2012) Atmospheric PCDD/F concentrations in 38 cities of China monitored with pine needles, a passive biosampler. Environmental Science \& Technology 46:13334-13343. https://doi.org/10.1021/es303468y

Choi SD (2014) Time trends in the levels and patterns of polycyclic aromatic hydrocarbons (PAHs) in pine bark, litter, and soil after a forest fire. Science of The Total Environment 470-471:1441-1449. https://doi.org/10.1016/j.scitotenv.2013.07.100

Cutright TJ (1995) Polycyclic aromatic hydrocarbon biodegradation and kinetics using Cunninghamella echinulata var. elegans. International Biodeterioration \& Biodegradation 35:397-408. https://doi.org/10.1016/0964-8305(95)00046-1

Dameng L, Zhihua L, Yunyong L (2011) Distribution and occurrence of polycyclic aromatic hydrocarbons from coal combustion and coking and its impact on the environment. Energy Procedia 5:734-741. https://doi.org/10.1016/j.egypro.2011.03.129

De Nicola F, Claudia L, MariaVittoria P, Giulia M, Anna A (2011) Biomonitoring of PAHs by using Quercus ilex leaves: source diagnostic and toxicity assessment. Atmospheric Environment 45:1428-1433. https://doi.org/10.1016/j.atmosenv.2010.12.022 
Esen F, Tasdemir Y, Vardar N (2008) Atmospheric concentrations of PAHs, their possible sources and gas-to-particle partitioning at a residential site of Bursa, Turkey. Atmospheric Research 88:243-255. https://doi.org/10.1016/j.atmosres.2007.11.022

European Community (2002) 2002/657/EC: Commission decision of 14 August 2002 implementing council directive 96/23/EC concerning the performance of analytical methods and the interpretation of results (notified under document number $\mathrm{C}(2002)$ 3044)

Fernández-Varela R, Ratola N, Alves A, Amigo JM (2015) Relationship between levels of polycyclic aromatic hydrocarbons in pine needles and socio-geographic parameters. Journal of Environmental Management 156:52-61. https://doi.org/10.1016/j.jenvman.2015.03.019

Galarneau E (2008) Source specificity and atmospheric processing of airborne PAHs: Implications for source apportionment. Atmospheric Environment 42:8139-8149. https://doi.org/10.1016/j.atmosenv.2008.07.025

Haritash AK, Kaushik CP (2009) Biodegradation aspects of polycyclic aromatic hydrocarbons (PAHs): a review. Journal of Hazardous Materials 169:1-15. https://doi.org/10.1016/j.jhazmat.2009.03.137

Hopkins J (1989) IARC monographs on the evaluation of carcinogenic risks to humans. Food and Chemical Toxicology 27:549-550. https://doi.org/10.1016/0278-6915(89)90054-9

International Agency for Research on Cancer (ed) (1983) Polynuclear aromatic compounds: this publication represents the views and expert opinions of an IARC working group on the evaluation of the carcinogenic risk of chemicals to humans which met in Lyon. Pt. 1: Chemical, environmental and experimental data. International Agency for Research on Cancer, Lyon

Jilin Province Statistics Bureau Data Management Center (2020) Statistic bureau of Jilin. http://tjj.jl.gov.cn/tjjj/. Accessed 12 Jul 2020

Jin XZ, Kaw HY, Li HJ, Wang Z, Zhao JH, Piao XF, Jin DR, He M (2020) A traceless cleanup method coupled with gas chromatography and mass spectrometry for analyzing polycyclic aromatic hydrocarbons in complex plant leaf matrices. Analyst 145:32663273. https://doi.org/10.1039/D0AN00128G

Johnsen AR, Wick LY, Harms H (2005) Principles of microbial PAH-degradation in soil. Environmental Pollution 133:71-84. https://doi.org/10.1016/j.envpol.2004.04.015

Korfmacher WA, Natush D, Taylor D, Whery E, Mamantov G (1979) Thermal and photochemical decomposition of particulate polycyclic aromatic hydrocarbons. 
Polynuclear Aromatic Hydrocarbons 165-169.

Kästner M, Breuer-Jammali M, Mahro B (1998) Impact of inoculation protocols, salinity, and $\mathrm{pH}$ on the degradation of polycyclic aromatic hydrocarbons (PAHs) and survival of PAH-degrading bacteria introduced into soil. Applied and Environment Microbiology 64:359-362. https://doi.org/10.1128/AEM.64.1.359-362.1998

Kim SJ, Lee H, Kwon JH (2014) Measurement of partition coefficients for selected polycyclic aromatic hydrocarbons between isolated plant cuticles and water. Science of The Total Environment 494-495:113-118. https://doi.org/10.1016/j.scitotenv.2014.06.119

Kong SF, Li XX, Li L, Yin Y, Chen K, Yuan L, Zhang YJ, Shan YP, Ji YQ (2015) Variation of polycyclic aromatic hydrocarbons in atmospheric PM2.5 during winter haze period around 2014 Chinese Spring Festival at Nanjing: Insights of source changes, air mass direction and firework particle injection. Science of The Total Environment 520:59-72. https://doi.org/10.1016/j.scitotenv.2015.03.001

Kuusimäki L, Peltonen Y, Kyyrö E, Mutanen P, Peltonen K, Savela K (2002) Exposure of garbage truck drivers and maintenance personnel at a waste handling centre to polycyclic aromatic hydrocarbons derived from diesel exhaust. Journal of Environmental Monitoring 4:722-727. https://doi.org/10.1039/B203443N

Lao JY, Xie SY, Wu CC, Bao LJ, Tao S, Zeng EY (2018) Importance of dermal absorption of polycyclic aromatic hydrocarbons derived from barbecue fumes. Environmental Science \& Technology 52:8330-8338. https://doi.org/10.1021/acs.est.8b01689

Lehndorff E, Schwark L (2004) Biomonitoring of air quality in the Cologne Conurbation using pine needles as a passive sampler-Part II: polycyclic aromatic hydrocarbons (PAH). Atmospheric Environment 38:3793-3808. https://doi.org/10.1016/j.atmosenv.2004.03.065

Li QQ, Chen BL (2014) Organic pollutant clustered in the plant cuticular membranes: visualizing the distribution of phenanthrene in leaf cuticle using two-photon confocal scanning laser microscopy. Environmental Science \& Technology 48:4774-4781. https://doi.org/10.1021/es404976c

Li XZ, Yang Y, Xu X, Xu CQ, Hong JL (2016) Air pollution from polycyclic aromatic hydrocarbons generated by human activities and their health effects in China. Journal of Cleaner Production 112:1360-1367. https://doi.org/10.1016/j.jclepro.2015.05.077

Librando V, Perrini G, Tomasello M (2002) Biomonitoring of atmospheric PAHs by evergreen plants: correlations and applicability. Polycyclic Aromatic Compounds 22:549-559. https://doi.org/10.1080/10406630290103726 
Liu B, Xue ZQ, Zhu XL, Jia CR (2017) Long-term trends (1990-2014), health risks, and sources of atmospheric polycyclic aromatic hydrocarbons (PAHs) in the U.S. Environmental Pollution 220:1171-1179. https://doi.org/10.1016/j.envpol.2016.11.018

Navarro-Ortega A, Ratola N, Hildebrandt A, Alves A, Lacorte S, Barcel ó D (2012) Environmental distribution of PAHs in pine needles, soils, and sediments. Environmental Science and Pollution Research 19:677-688. https://doi.org/10.1007/s11356-011-0610-5

Noth EM, Katharine Hammond S, Biging GS, Tager IB (2013) Mapping and modeling airborne urban phenanthrene distribution using vegetation biomonitoring. Atmospheric Environment 77:518-524. https://doi.org/10.1016/j.atmosenv.2013.05.056

Ockenden WA, Steinnes E, Parker C, Jones KC (1998) Observations on persistent organic pollutants in plants: Implications for their use as passive air samplers and for POP cycling. Environmental Science \& Technology 32:2721-2726. https://doi.org/10.1021/es980150y

Odabasi M, Ozgunerge Falay E, Tuna G, Altiok H, Kara M, Dumanoglu Y, Bayram A, Tolunay $\mathrm{D}$, Elbir T (2015) Biomonitoring the spatial and historical variations of persistent organic pollutants (POPs) in an industrial region. Environmental Science \& Technology 49:2105-2114. https://doi.org/10.1021/es506316t

Paterson S, Mackay D, Bacci E, Calamari D (1991) Correlation of the equilibrium and kinetics of leaf-air exchange of hydrophobic organic chemicals. Environmental Science \& Technology 25:866-871. https://doi.org/10.1021/es00017a006

Pérez-Harguindeguy N, Díaz S, Garnier E, Lavorel S, Poorter H, Jaureguiberry P, Bret-harte MS, Cornwell WK, Craine JM, Gurvich DE, Urcelay C, Veneklaas EJ, Reich PB, Poorter L, Wright IJ, Ray P, Enrico L, Pausas JG, de Vos AC, Buchmann N, Funes G, Quétier F, Hodgson JG, Thompson K, Morgan HD, ter Steege H, Sack L, Blonder B, Poschlod P, Vaieretti MV, Conti G, Staver AC, Aquino S, Cornelissen JHC (2013) New handbook for standardised measurement of plant functional traits worldwide. Australian Journal of Botany 61:167. https://doi.org/10.1071/BT12225

Piccardo MT, Pala M, Bonaccurso B, Stella A, Redaelli A, Paola G, Valerio F (2005) Pinus nigra and Pinus pinaster needles as passive samplers of polycyclic aromatic hydrocarbons. Environmental 133:293-301. https://doi.org/10.1016/j.envpol.2004.05.034

Ratola N, Amigo JM, Alves A (2010a) Comprehensive assessment of pine needles as bioindicators of PAHs using multivariate analysis. The importance of temporal trends. Chemosphere 81:1517-1525. https://doi.org/10.1016/j.chemosphere.2010.08.031 
Ratola N, Amigo JM, Alves A (2010b) Levels and sources of PAHs in selected sites from Portugal: biomonitoring with Pinus pinea and Pinus pinaster needles. Archives of Environmental Contamiantion and Toxicology 58:631-647. https://doi.org/10.1007/s00244-009-9462-0

Ratola N, Amigo JM, Oliveira MSN, Araújo R, Silva JA, Alves A (2011) Differences between Pinus pinea and Pinus pinaster as bioindicators of polycyclic aromatic hydrocarbons. Environmental and Experimental Botany 72:339-347. https://doi.org/10.1016/j.envexpbot.2011.04.012

Rodgman A, Smith CJ, Perfetti TA (2000) The composition of cigarette smoke: a retrospective, with emphasis on polycyclic components. Human \& Experimental Toxicology 19:573595. https://doi.org/10.1191/096032700701546514

Roslund MI, Grönroos M, Rantalainen AL, Jumpponen A, Romantschuk M, Parajuli A, Hyöty H, Laitinen O, Sinkkonen A (2018) Half-lives of PAHs and temporal microbiota changes in commonly used urban landscaping materials. PeerJ 6:e4508. https://doi.org/10.7717/peerj.4508

Shapiro SS, Wilk MB (1965) An analysis of variance test for normality (complete samples). Biometrika 52:591. https://doi.org/10.2307/2333709

Taiz L, Zeiger E (2010) Plant physiology, 5th ed. Sinauer Associates, Sunderland, MA

Tomashuk TA, Truong TM, Mantha M, McGowin AE (2012) Atmospheric polycyclic aromatic hydrocarbon profiles and sources in pine needles and particulate matter in Dayton, Ohio, USA. Atmospheric Environment 51:196-202. https://doi.org/10.1016/j.atmosenv.2012.01.028

Wammer KH, Peters CA (2005) Polycyclic aromatic hydrocarbon biodegradation rates: A structure-based study. Environmental Science \& Technology 39:2571-2578. https://doi.org/10.1021/es048939y

Wang DG, Chen JW, Xu Z, Qiao XL, Huang LP (2005) Disappearance of polycyclic aromatic hydrocarbons sorbed on surfaces of pine [Pinua thunbergii] needles under irradiation of sunlight: Volatilization and photolysis. Atmospheric Environment 39:4583-4591. https://doi.org/10.1016/j.atmosenv.2005.04.008

Wang XP, Xu BQ, Kang SC, Cong ZY, Yao TD (2008) The historical residue trends of DDT, hexachlorocyclohexanes and polycyclic aromatic hydrocarbons in an ice core from Mt. Everest, central Himalayas, China. Atmospheric Environment 42:6699-6709. https://doi.org/10.1016/j.atmosenv.2008.04.035

Yang B, Liu S, Liu Y, Li XF, Lin XB, Liu M, Liu XR (2017) PAHs uptake and translocation in 
Cinnamomum camphora leaves from Shanghai, China. Science of The Total Environment 574:358-368. https://doi.org/10.1016/j.scitotenv.2016.09.058

Yang C, Piao XF, Qiu JX, Wang XP, Ren CY, Li DH (2011) Gas purge microsyringe extraction for quantitative direct gas chromatographic-mass spectrometric analysis of volatile and semivolatile chemicals. Journal of Chromatography A 1218:1549-1555. https://doi.org/10.1016/j.chroma.2011.01.018

Yang P, Chen J, Wang Z, Qiao XL, Cai XY, Tian FL, Ge LK (2007) Contributions of deposited particles to pine needle polycyclic aromatic hydrocarbons. Journal of Environmental Monitoring 9:1248-1253. https://doi.org/10.1039/b708508g

Zhao X, He M, Shang HB, Yu HL, Wang H, Li HJ, Piao JY, Quinto M, Li DH (2018) Biomonitoring polycyclic aromatic hydrocarbons by Salix matsudana leaves: A comparison with the relevant air content and evaluation of environmental parameter effects. Atmospheric Environment 181:47-53. https://doi.org/10.1016/j.atmosenv.2018.03.004

Zhao X, Kim SK, Zhu WH, Kannan N, Li DH (2015) Long-range atmospheric transport and the distribution of polycyclic aromatic hydrocarbons in Changbai Mountain. Chemosphere 119:289-294. https://doi.org/10.1016/j.chemosphere.2014.06.005

Zhou L, Dong L, Huang Y, Shi SX, Zhang LF, Zhang XL, Yang WL, Li LL (2014) Spatial distribution and source apportionment of polycyclic aromatic hydrocarbons (PAHs) in camphor (Cinnamomum camphora) tree bark from Southern Jiangsu, China. Chemosphere 107:297-303. https://doi.org/10.1016/j.chemosphere.2013.12.070 


\section{Supplementary Files}

This is a list of supplementary files associated with this preprint. Click to download.

- Supplementaryinformation.docx 